\title{
LOCUS OF CONTROL AND ENTREPRENEURSHIP IN THE RUSSIAN REPUBLIC
}

By: Patrick J. Kaufmann, Dianne H.B. Welsh, and Nicholas Bushmarin

Kaufmann, P.J., Welsh, D.H.B., \& Bushmarin, N. (1995, Fall). Locus of control and entrepreneurship in the Russian Republic. Entrepreneurship Theory and Practice, 20(1), 43-56.

Made available courtesy of BLACKWELL PUBLISHING LTD. The definitive version is available at www.blackwell-synergy.com

***Note: Figures may be missing from this format of the document

\section{LOCUS OF CONTROL AND ENTREPRENEURSHIP IN THE RUSSIAN REPUBLIC}

\section{INTRODUCTION}

Since Rotter (1954) first introduced his theory of social learning, there has developed an extensive body of research surrounding the central construct of locus of control. Perceived internal locus of control is defined as the personal belief that one has influence over outcomes through ability, effort, or skills; whereas external locus of control is the belief that external forces control outcomes. Some of that research has linked a belief in the internal control over the events in one's life to an individual's propensity to engage in entrepreneurial activity (e.g., Berlew 1975; Shapero 1975; Rupke 1978; Brockhaus 1982; Gartner 1985; Perry 1990; Shaver and Scott 1991).

The initially posited unidimensionality of the locus of control construct (i.e., internal vs external control) has been questioned repeatedly, giving rise to more elaborate conceptualizations (Lefcourt 1981). While the internal anchor of the I-E scale has remained relatively intact, the external orientation has been split theoretically into the two (arguably) discrete dimensions of Chance and Powerful Others (Levenson 1974).

The specific identification of Powerful Others as a unique dimension of the attribution to external forces makes the locus of control construct particularly useful in cross-cultural psychological research relating to entrepreneurship because of differences among political philosophies with respect to personal freedom, the role of the individual in society, and the 
appropriateness and importance of entrepreneurial activity in the economies of the focal countries. Consequently, along with the general domestic studies examining the correlation between locus of control and entrepreneurship or other variables, there have been a number of cross-cultural/cross-national studies establishing and comparing base-line scores on the IPC scale (See Table 1). These studies now provide data for IPC scales translated into Chinese, Japanese, Hindi, Portuguese, Italian, and German. Unfortunately, none of these studies have included entrepreneurial activity in their examinations.

This paper reports the results of an IPC scale locus of control study conducted in the Russian Republic of the former Soviet Union in the Spring of 1990. The motivation for this study is provided by the suggested, though disputed, association between psychological trait variables and entrepreneurial activity (Berlew 1975; Shapero 1975; Brockhaus 1982; Gartner 1985; Perry 1990; Shaver and Scott 1991; But see Brockhaus and Nord 1979; Begley and Boyd 1987), and the generally acknowledged need for entrepreneurial activity in the dramatically changing and challenging Russian Republic. As possible future-entrepreneurs, we administered the IPC scale locus of control to students as well as entrepreneurs actively doing business. Since most international research with the scale has been conducted with students, it could provide an interesting comparison between countries as well as between students and entrepreneurs in the Russian Republic.

By all accounts - cultural, political, social, and economic- the Russian Republic represents a country in transition. Jick (1992) has described the environment as one of "transformational change," where the magnitude of change represents a total abandonment of traditional behavior, expectations, and theories in favor of completely new alternatives or innovations. Practitioner work in this area has been popularized under the slogan of "Paradigm Shifts" (Barker, 1992). Much attention has been given in the popular press to such dramatic changes and challenges facing the new entrepreneurs in the Russian Republic. If they are to succeed, entrepreneurs must be 
understood, encouraged, and nurtured. Indeed, the success of the country's economic restructuring efforts depends heavily on the success and nurturing of budding entrepreneurs. However, there is still very little empirical studies of entrepreneurs in these newly emerging countries or any cross cultural studies that compare them to entrepreneurs in the West. This has been despite a strong call for such international research (Alder, 1991).

Although researchers have examined recent changes in Russian culture (Welsh 1991; Vance and Zhuplev 1992), leadership (Puffer 1994), and management (Lawrence and Vlachoutsicos 1990; Smith 1990; Ivancevich, DeFrank, and Gregory 1992; McCarthy and Puffer 1992; Puffer 1992; Silverman, Vogt and Yanowitch 1992; Welsh and Swerdlow 1992; Luthans, Welsh and Rosenkrantz 1993; Shama 1993; Torevski and Morgan 1993; Walck, 1994; Welsh, Luthans and Sommer 1993a, 1993b; Welsh, Sommer and Birch 1993), to date, there has been only one study examining entrepreneurship (McCarthy, Puffer, and Shekshnia 1993). No study has yet to focus on the psychological traits that these much needed entrepreneurs possess, and whether they differ from other entrepreneurs world- wide. Both Puffer (1994) and Walck (1994) urgently call for such research to better understand Russian entrepreneurs. Such information could have a direct effect on the success of joint ventures and economic aid for training and development as Russia shifts from a planned economy to a demand economy. The purpose of the present study is to describe the psychological traits, in particular, locus of control, of a sample of Russian students and entrepreneurs. Some comparisons are made between the results of this study and studies in other countries.

\section{PSYCHOLOGICAL IMPEDIMENTS TO ENTREPRENEURSHIP IN RUSSIA}

An internal locus of control has been one of the psychological traits most often posited as predictive of entrepreneurship (Perry 1990). Typically, studies of this link have used Rotter's (1966) I-E scale. For example, Shapero (1975) found that entrepreneurs tended to have an internal focus, and Nelson (1991) found that female entrepreneurs have a significantly more 
internal locus of control than do females in the general population. Bonnet and Furnham (1991) used a three dimensional (Internal, External and Chance) economic locus of control scale developed by Banks (1989) and found a significant difference between the locus of control of a group of student entrepreneurs and a control group. Levin and Leginsky (1990) used Levenson's (1974) IPC scale and found that entrepreneurial social workers tended to exhibit a greater internal locus of control. In a 1978 study comparing entrepreneurs with employee/managers, Rupke used both Rotter's I-E scale and Levenson's IPC scale. He found entrepreneurs to display significantly higher levels of internal locus of control than the non-entrepreneurs with both measures.

With the collapse of the Soviet Union, the successful replacement of its planned economy with a quasi-free market system will depend to a great extent on the development of a culture of entrepreneurship. The likelihood of entrepreneurial activity, in turn, may depend (at least in part) on perceptions of personal control among future Russian business leaders.

A relatively small number of Russians have already begun the process of privatization, and there does exist growing evidence of entrepreneurship in the former Soviet Union (Banerjee 1993; Gumbel 1993; Ignatius 1993; McCarthy, Puffer and Shekshnia 1993). If the link between entrepreneurial activity and perceived locus of control is not completely culturally context specific, those Russians who have already begun to engage in entrepreneurial activity should report the same elevated perception of Internal control (I) when compared with Chance (C) and Powerful Others (P) as do U.S. entrepreneurs (Nelson 1991). Thus,

H1:Russian entrepreneurs will locate control over the events of their lives more Internally (I) and less in Powerful Others (P) and in Chance (C).

Arguably the most important situational variable in predicting global entrepreneurial activity is the country and culture of origin. This variable reflects not only the social-psychological context, but also the economic and political opportunities faced by potential entrepreneurs. Holding that situational context constant however, it is possible to use the IPC 
construct to compare entrepreneurial and non-entrepreneurial populations within a particular culture. Russian entrepreneurs' should demonstrate the same locus of control traits when compared with the general population of non-entrepreneurial Russian students as do entrepreneurs in other cultures (Shapero 1975; Rupke 1978). Thus,

\section{H2:Russian entrepreneurs will locate control over the events of their lives more Internally (I) and less in Powerful Others (P) than Russian students.}

When this most important situational feature is varied, i.e., when Russian entrepreneurs and students are compared with entrepreneurs and students never exposed to a centrally planned economy, the impact should be evident in their perceived locus of control. Numerous reports out of Russia indicate the hardest working, most successful entrepreneurs are young individuals with little experience with the communist bureaucracy (Puffer, 1994). Walk (1994) reinforces this claim by suggesting that age may be a major factor in determining entrepreneurial success. Seventy years of central management by a strong, but ultimately inefficient, bureaucratic system is likely to have enhanced the Russian people's perceptions of control over their lives by powerful others and chance. ${ }^{1}$ In fact, in their survey of 40 founders of new enterprises in Russia, McCarthy, Puffer and Shekshnia (1993) found that the respondent entrepreneurs considered intervention by a still powerful government to be their greatest obstacle, and generally followed a strategy which relied on chance to identify business opportunities. Consequently, although Russian entrepreneurs may possess a greater perceived Internal Locus of Control (I) than they do of either Powerful Others $(\mathrm{P})$ or Chance $(\mathrm{C})$, the reality of their experience in attempting to open their new businesses should have tempered this in comparison with entrepreneurs operating in less bureaucratic economies. To the extent that this experience has been observed by the general population, the same pattern should emerge for student respondents. Thus,

\footnotetext{
1 For a complete historical account of the cultural, political, social and economic changes that have taken place in the former Soviet system, see Kiezun, 1991.
} 


\section{H3(a):Russian entrepreneurs will locate control over the events of their lives more in Powerful Others (P) and Chance (C) and less Internally (I) than entrepreneurs from historically democratic countries.}

\section{H3(b):Russian students will locate control over the events of their lives more in Powerful Others (P) and Chance (C) and less Internally (I) than students from historically democratic countries.}

\section{THE STUDY}

Levenson's (1974) IPC scale was translated and retranslated into Russian by a Russian born U.S. professor, two American professors of Russian, and a Russian citizen with translation experience. The scale was then back translated into English following the procedures recommended by Earley (1989). The subjects consisted of 76 male and 50 female undergraduate students (average age 23 years) at Tver State University (a regional university of 8,000 students) and Moscow State University (one of the largest and most prestigious universities in Russia), and 105 male and 67 female members (average age 27 years)of the Tver Cooperative Association. That organization consists of owners and co-owners of privately held enterprises, or entrepreneurial ventures, in the city of Tver (formerly known as Kalinin, approximately 90 miles Northwest of Moscow). ${ }^{2}$ The members, therefore, arguably provide the closest approximation to a sample of business entrepreneurs available in the Russian Republic. The survey was administered by one of the authors at the beginning of various classes for the students and at the beginning of the monthly meeting of the Tver Cooperative Association held the same week for the entrepreneurs. The subjects were advised that the survey was voluntary and anonymous. The subjects were allowed as much time as they needed to complete the survey.

The mean scores and standard deviations for Russian men and women entrepreneurs and students for the IPC scales are presented in Table 1. Scores could range from 0-48 for each scale,

\footnotetext{
2 The sample also contains similar respondents from some entrepreneurial enterprises that were not officially members of the Tver Cooperative Organization at the time of the survey.
} 
and had Chronbach alpha values for I $(\alpha=.5667), P(\alpha=.6634)$, and $C(\alpha=.4752)$. The scales were somewhat more reliable in the entrepreneur sample than in the student sample.

The IPC scale posits 3 dimensions to the locating control over ones' life. Underlying those three dimensions is the general distinction between those controling factors that are internal to the person and those external. The data in this study were examined to determine whether they exibited those characteristics. As expected, I was negatively correlated with $\mathrm{P}(\mathrm{p}<.01)$, and $\mathrm{P}$ and $\mathrm{C}$ were positively correlated $(\mathrm{p}<.01)$, however I was not significantly negatively correlated with C as expected (see Lao 1977; Jutras 1987; Singh and Chaudhary 1984 and Hong and Bartenstein 1982 for similar analysis and results in cross-cultural IPC research). The oblique rotated factor analysis for a three factor solution is reported in Table 2. Although there was some cross-loading, the internal (I) dimension (Factor 3 ) and the Powerful Other (P) dimension (Factor 1) did emerge. The data were also subjected to confimatory factor analysis to determine whether a two factor model was equally descriptive of the data. The items were forced to load on the hypothesized IPC dimensions in the three factor model and the P and C factors were collapsed in the nested two factor model. The $\chi^{2}$ for the 3 factor model was 622.95 , df. 249, with a GFI of .845. The $\chi^{2}$ for the nested 2 factor model was 661.23 , df. 251 with a GFI of .834 . The $\chi^{2}$ difference, therefore, was 38.28, df.2, and was highly significant. The three factor model, although somewhat equivocal in its interpretation, was significantly better at describing the data than the two factor model.

As predicted in $\mathrm{H} 1$, Russian entrepreneurs reported significantly higher levels of perceived Internal control (I) than either Powerful Others (P) or Chance $(\mathrm{C})(\mathrm{p}<.01)$. The difference between I and P was not significant for the male subgroup, but was significant for females and the male/female combined group $(\mathrm{p}<.01)$. The difference between I and $\mathrm{C}$ was significant for all subgroups $(\mathrm{p}<.01)$.

Contrary to the results predicted in H2, Russian entrepreneurs scored lower than Russian 
students on the internal scale. This effect was stronger for male than female respondents, but was significant for both $(\mathrm{p}<.05)$. Moreover, male entrepreneurs scored higher on the powerful other scale than male students, while female entrepreneurs scored lower on the chance scale than female students $(\mathrm{p}<.05)$.

Table 3 presents a series of t-tests of differences between the Russian results and previously published cross-cultural IPC data. Consistent with H3(a) and (b), Russian entrepreneurs and students generally scored lower on the internal scale than their counterparts in most other countries. ${ }^{3}$ Russian entrepreneurs scored significantly lower than U.S. entrepreneurs

\section{DISCUSSION}

This study answers the call for international research in entrepreneurship. Significant support was found for 3 of the 4 hypotheses. As suggested in Hypothesis 1, Russian entrepreneurs did locate control internally, and this perception of personal control dominated the control they felt coming from powerful others or from chance. This, then, provides some support for the notion that perceptions of self reliance may be a necessary, if not sufficient, condition for entrepreneurial activity. Nevertheless, as suggested in H3(b), cultural history has lasting effects. For Example, Russian students were more likely to attach control to powerful others and to chance when compared with students from historically democratic countries.

Perhaps the most relevant and striking comparison in this study was between the U.S. and Russian entrepreneurs. As expected in H3(a), although the Russian respondents scored higher on the internal scale than on the other two scales, they scored significantly lower on the internal scale

\footnotetext{
3 There were exceptions to this rule. Brazilian non-students scored lower on all three dimensions, as did New Zealand students. When compared to students in both Italy and Germany, Russian students cored lower on the internal scale and higher on the powerful other and chance scales. This pattern was reversed for Japanese students, where Russian students scored higher on the internal scale and lower on the other two scales, but because variance was not reported in that study, it was not possible to determine if those differences were significant.
} 
than the U.S. sample. The Russian entrepreneurs also scored significantly higher on the powerful other and chance scores than the U.S. entrepreneur sample. Even more interesting was the fact that the U.S. employee manager control group scored significantly higher on the internal scale and lower on the other scales than the Russian entrepreneurs. Two interpretations seem reasonable. First, the cultural base rate of locus of control perceptions biases the comparison of Russian and U.S. entrepreneurial data so that even if some Russians feel significant control over their own lives, the long history of individual rights among all individuals in the U.S. tends to dominate. Second, it is possible that the attractiveness of self-enterprise is so great currently in Russia that individuals will engage in entrepreneurial activity if possible, even when they have serious doubts about their own ability to control the outcome of that effort.

It is interesting to note that, contrary to $\mathrm{H} 2$, Russian students scored higher than actual entrepreneurs on the internal locus of control. One interpretation is encouraging. It is quite likely that perceptions of the locus of control are fairly stable within individuals over time. These are perceptual responses that are learned over long periods and reflect the individual history of the respondent or respondent group. Today's Russian entrepreneurs grew up and formed their values and aspirations under the old system. They were able to find the entrepreneurial spirit from within, but had little support for this from their environment. Russian students in 1991 were forming values and aspirations at a time of great change and awakening in the Soviet Union. It is quite possible that the base rates for the Russian population are shifting toward a more western profile. If there is a causal connection leading from the perception of personal control to entrepreneurial activity, therefore, the emergence of a generation of Russians even more prone to such an attribution than existing Russian entrepreneurs may bode well for the change to a free enterprise system. Another interpretation of the findings is not so encouraging. It is also possible that the difficulties encountered in creating new enterprises in Russia have caused Russian entrepreneurs to become more cynical and question their control over that process more 
than students who have yet to try.

\section{IMPLICATIONS FOR FUTURE RESEARCH}

This study has provided the first test of the locus of control construct in Russia with students and entrepreneurs. Support in this study for the general proposition that a higher level of perceived Internal Locus of Control leads to a greater likelihood of entrepreneurial activity is somewhat ambiguous. Psychological trait effects are often swamped by situational effects, and this study suffers from the problems typical of any study attempting to use psychological trait variables to predict behavior. These issues were even more difficult to deal with here because the ability to gather rich, descriptive, situational data is so limited in formerly closed countries like Russia in 1991. Nevertheless, it may be more useful to think of the Locus of Control construct as a social-psychological phenomenon. If so, cross-cultural and longitudinal comparisons may offer more insight into its relationship with more general social and economic patterns, including such phenomena as entrepreneurial activity. Such comparisons could be useful in identifying students with strong levels of perceived Internal Locus of Control and their interests in entrepreneurship. Also, such comparisons between countries would be helpful in teaching entrepreneurship to the former eastern bloc countries.

Because of the timing of the data collection in this study, i.e., immediately preceding the official breakup of the Soviet Union, the data reported here may provide the basis for interesting future longitudinal analyses as perestoika becomes increasingly internalized by Russian citizens, and entrepreneurship becomes more entrenched in the Russian psyche. If so, it could help to initiate an examination of the process by which a population becomes more confident in its ability to control its economic environment. In conclusion, this study provides an initial set of data on the relationship between a familiar psychological trait variable and the likelihood of entrepreneurial activity in a rapidly changing economy of the Russian Republic. This basic research should be used as a point of departure for future cross-cultural studies on the 
psychological traits of students and entrepreneurs in the former eastern bloc countries. 


\section{References}

Alder, N.J. International Dimensions of Oranizational Behavior, 2nd edition, 1991, Boston: Kent Publishing.

Banerjee, N. The "from Russia with love' boat isn't your ordinary tourist dive, Wall Street Journal, 1993, April 30, B1.

Banks, M.H. Beliefs about economic success. ESRC 16-19 Initiative, Occasional papers (2), 1989.

Barker, J. Future Edge - Discovering the New Rules of Success, $\quad$ 1992, New York: Morrow Williams \& Company.

Begley, T., \& Boyd, D. Psychological characteristics associated with performance in entrepreneurial firms and small businesses. Journal of Business Venturing, 1987, 2, 79-93.

Berlew, D. The nature of entrepreneurs. Proceedings of project ISEED (International Symposium on Entrepreneurship and Enterprise Development) Sponsored by the Ohio Entrepreneurship Office, Columbus, Ohio, 1975, 42-44.

Borg, I., \& Elizur, D. Job insecurity: Correlates, moderators, and measurement. International Journal of Manpower, 1992, $\quad$ 13, 13-26.

Brockhaus, R.H. The psychology of the entrepreneur. In C. A. Kent, D. L. Sexton, \& K. H. Vesper (Eds.), Encyclopedia of Entrepreneurship, Englewood Cliffs, NJ: Prentice Hall, 1982. Pp. 39-56.

Brockhaus, R.H., \& Nord, W.R. An exploration of factors affecting the entrepreneurial decision: Personal characteristics versus environmental conditions. Proceedings of the National Academy of Management, 1979, pp. 364-368.

Bonnet, C., \& Furnham, A. Who wants to be an entrepreneur? A study of adolescents interested in a Young Enterprise scheme. Journal of Economic Psychology, 1991, 12, 465-478.

Cole, D. \& Cole, S. Locus of control and cultural conformity: On going against the norm. Personality and Social Psychology Bulletin, 1974, 1, 351-353.

Collins, B. Four components of the Rotter Internal-External Scale: Belief in a difficult world, a just world, a predictable world, and a politically responsive world. Journal of 
Personality and Social Psychology, 1974, 29, 381-391.

Dela Coleta, M.F. Escala multidimensional de locus de control de Brasileiros de Psicologia, 1987, 39,

Levenson. Arquivos 79-97.

Earley, P.C. Social loafing and collectivism: A comparison of the United States and the Peoples' Republic of China, Administrative Science Quarterly, 1989, 34, 565-580.

Gali, I., Nigro, G. \& Krampden, G. Multidimensional locus of control and Machiavellianism in Italian and West German students: Similarities and differences. International

Review of Applied Psychology, 1986, 35, 453-461.

Gartner, W.B. A conceptual framework for describing the phenomenon of new venture creation. Academy of Management Review, 1985, 10, 696-706.

Gumbel, P. Russia's Pulse: Writhes with change as referendum nears, The Wall Street Journal, 1993, April 16, A1,A8.

Gurin, P., Gurin, G., Lao, R.C., \& Beattie, M. Internal- external control in motivational dynamics of Negro youth. Journal of Social Issues, 1969, 25, 29-53.

Hong, S.M., \& Bartenstein, C. Dimensions of Levenson's locus of control with Australian high school students. Psychological Reports, 1982, 51, 395-400.

Hyman, G.J., Stanley, R. \& Burrows, G.D. The relationship between three multidimensional locus of control scales. Educational and Psychological Measurement, 1991, 51, 403-412.

Ignatius, A. Scraping by: Despite their woes, Russians somehow find ways to cope, The Wall Street Journal, 1993, January 29, A1, A2.

Ivancevich, J.D., DeFrank, R.S. \& Gregory, P.R. The Soviet Enterprise Director: An important resource before and after the coup. Academy of Management Executive, 1992, 6, 42-55.

Jick, T. Managing change: Cases and concepts, 1992, Homewood, IL: Irwin.

Jutras, S. L'Ipah version canadienne-francaise de l'Echelle de Levenson mesurant le lieu de controle tridimensionnel. Canadian Journal of Behavioral Science, 1987, 19, 74-85.

Kiezun, W. Management in socialist countries: USSR and Central Europe, 1991, New 
York: Walter de Gruyter.

Lao, R.C. Levenson's IPC (internal-external control) scale. Journal of Cross-Cultural Psychology, 1977, 9, 113-124.

Lawrence, P. \& Vlachoutsicos, C.A. Behind the factory walls: Decision making in Russian and U.S. enterprises, 1990, Boston: Harvard Business School Press.

Lefcourt, H.M. Overview. Research with the Locus of Control Construct. Vol. 1, New York: Academic Press, 1981. Pp. 1- 11.

Levenson, H. Differentiating among internality, powerful others, and chance. In H.M. Lefcourt (Ed.), Research with the Locus of Control Construct. Vol. 1, New York: Academic Press, 1981. Pp.15-63.

Levenson, H. Activism and powerful others: Distinctions within the concept of internal-external control. Journal of Personality Assessment, 1974, 38, 377-383.

Levin, R., \& Leginsky, P. The independent social worker as entrepreneur. Journal of Independent Social Work, 1990, 5, 22-31.

Luthans, F., Welsh, D.H.B. \& Rosenkrantz, S.A. What do Russian managers really do? A cross-cultural comparison of successful and effective managers, Journal of International Business Studies, 1993, 24, 741-761.

Mahler, I. A comparative study of locus of control. $\quad$ Psychologia, 1974, 17, 135-139.

McCarthy, D.J. \& Puffer, S.M. Perestroika at the plant level, Columbia Journal of World Business, 1992, 27, 86-99.

McCarthy, D.J., Puffer, S.M. \& Shekshnia, S.V. The resurgence of an entrepreneurial class in Russia, Journal of Management Inquiry, 1993, 12, 125-137.

Mirels, H.L. Dimensions of locus of control. Journal of Consulting and Clinical Psychology, 1970, 34, 226-228.

Nelson, G. Locus of control for successful female small business proprietors. The Mid-Atlantic Journal of Business, 1991， 27, 213-224.

Perry, C. After further sightings of the Heffalump. Journal of Managerial Psychology, 1990 5, 22-31.

Puffer, S.M. (ed.) The Russian management revolution: Preparing managers for the market economy, 1992, Armonk, NY: M.E. Sharpe. 
Puffer, S.M. Understanding the bear: A portrait of Russian Management Executive, 1994, 8, 41-54. business leaders, Academy of

Rotter, J.B. Social learning and clinical psychology. Englewood Cliffs, NJ: Prentice Hall, 1954.

Rotter, J.B. Generalized expectancies for internal versus external control of reinforcement. Psychological Monographs, 1966, 80 (1, Whole No. 609).

Rupke, R.H. Entrepreneurial potential and assessments. Unpublished master's thesis, Pepperdine University, 1978.

Shama, A. Management under fire: The transformation of managers in the Soviet Union and Eastern Europe, Academy of Management Executive, 1993, 1, 22-35.

Shapero, A. The displaced, uncomfortable entrepreneur. Psychology Today, 1975, 83-88.

Shaver, K.G., \& Scott, L.R. Person, process, choice: The psychology of new venture creation. Entrepreneurship Theory and Practice, 1991, 23-45.

Sherman, M.F., \& Ryckman, R.M. Discriminant validity of Levenson's I and P scales: Used as predictors of causal attribution. Personality and Social Psychology Bulletin, $1980,6,57-62$.

Silverman, B., Vogt, R. \& Yanowitch, M. Labor and democracy in the transition to a market system, 1992, New York: M.E. Sharpe.

Singh, B.N., \& Chaudhary, P.N. Hindi adaptation of Levenson's multidimensional measures of locus of control. Indian Psychological Review, 1984, 26, 45-52.

Smith, H. The new Russians, 1990, New York: Random House.

Torevski, M. \& Morgan, E. Cutting the red tape, 1993, New York: The Free Press.

Vance, C.M. \& Zhuplev, A.V. Myths about doing business in the Russian Union, Journal of Management Inquiry, 1992, 1, 66-69.

Walck, C. Understanding the bear: Executive commentary. Academy of Management Executive, 1994, 8, 56-59.

Walkey, F.H. Internal control, powerful others, and chance: A confirmation of Levenson's factor structure. Journal of Personality Assessment, 1979, 43, 532-535. 
Welsh, D.H.B. The early days of Perestroika, in F. Luthans and R.M. Hodgetts, International Management, 1991, New York: McGraw Hill.

Welsh, D.H.B \& Swerdlow, S. Hospitality Russian style: Nine communication challenges, Cornell Hotel and Restaurant Administration Quarterly, 1992, 33, 64-72.

Welsh, D.H.B., Luthans, F. \& Sommer, S.M. Managing Russian factory workers: The impact of U.S.-based behavioral and participative techniques, Academy of Management

Journal, 1993a, 36, 58-79.

Welsh, D.H.B. Luthans, F. \& Sommer, S.M. Organizational behavior modification goes to Russia: Replicating an experimental analysis across cultures and tasks, Journal of

Organizational Behavior Management, 1993b, 13, 15-35.

Welsh, D.H.B., Sommer, S.M. \& Birch, N. Changing performance among Russian retail workers: Effectively transferring American management techniques, Journal of Organizational Change Management, 1993, 6, 37-53. 


\title{
LOCUS OF CONTROL AND ENTREPRENEURSHIP IN THE RUSSIAN REPUBLIC
}

\author{
Contact: Patrick J. Kaufmann \\ Marketing Department \\ College of Business Administration \\ Georgia State University \\ Atlanta, GA 30303-3083 \\ Tel. (404) 651-1978 \\ FAX (404) 651-4198 \\ Dianne H.B. Welsh \\ Eastern Washington University \\ Nicholas Bushmarin \\ Tver (Russia)State University
}

September 20, 1994 